\title{
Effectiveness of the flipped classroom on the development of self-directed learning in nursing education: a meta-analysis
}

Ya-Qian Liuª, Yu-Feng Lia, Meng-Jie Leia, Peng-Xi Liub, Julie Theobaldb, Li-Na Menga,

Ting-Ting Liü, Chun-Mei Zhang ${ }^{\mathrm{b}}$, Chang-De Jinb,*

aDepartment of Graduate, Tianjin University of Traditional Chinese Medicine, Tianiin 301617, China

${ }^{b}$ Department of Nursing, Tianjin University of Traditional Chinese Medicine, Tianjin 301617, China

Received: 20 February 2018; Accepted: 7 May 2018; Published: 20 Dec 2018

Abstract: 0bjectives: To examine the best practice evidence of the effectiveness of the flipped classroom (FC) as a burgeoning teaching model on the development of self-directed learning in nursing education.

Data sources: The relevant randomized controlled trial (RCT) and non-RCT comparative studies were searched from multiple electronic databases including PubMed, Embase, Web of Science, Cumulative Index to Nursing and Allied Health Literature (CINAHL), Cochrane Central Register of Controlled Trials (CENTRAL), Wanfang Data, China National Knowledge Infrastructure (CNKI), and Chinese Science and Technology Periodical Database (VIP) from inception to June 2017.

Review methods: The data were independently assessed and extracted for eligibility by two reviewers. The quality of included studies was assessed by another two reviewers using a standardized form and evaluated by using the Cochrane Collaboration's risk of bias tool. The self-directed learning scores (continuous outcomes) were analyzed by using the $95 \%$ confidence intervals (Cls) with the standard deviation average (SMD) or weighted mean difference (WMD). The heterogeneity was assessed using Cochran's ${ }^{2}$ statistic. Results: A total of 12 studies, which encompassed 1440 nursing students (intervention group $=685$, control group $=755$ ), were eligible for inclusion in this review. Of 12 included studies, the quality level of one included study was $A$ and of the others was B. The pooled effect size showed that compared with traditional teaching models, the FC could improve nursing students' selfdirected learning skill, as measured by the Self-Directed Learning Readiness Scale (SDLRS), Self-Directed Learning Readiness Scale for Nursing Education (SDLRSNE), Self-Regulated Learning Scale (SRL), Autonomous Learning Competencies scale (ALC), and Competencies of Autonomous Learning of Nursing Students (CALNS). Overall scores and subgroup analyses with the SRL were all in favor of the FC.

Conclusions: The result of this meta-analysis indicated that FCs could improve the effect of self-directed learning in nursing education. Future studies with more RCTs using the same measurement tools are needed to draw more authoritative conclusions.

Keywords: flipped classroom • blended learning $\bullet$ reverse teaching $\bullet$ self-directed learning $\bullet$ self-learning ability $\bullet$ self-management $\bullet$ nursing education - meta-analysis

(c) Shanxi Medical Periodical Press.

\section{Introduction}

In a complex health care environment where social, technological, and medical changes present them with huge challenges at a rapid pace, nurses are expected to strengthen their self-directed learning ability to ensure

* Corresponding author.

E-mail: jcd1886@sina.cn (C. -D. Jin).

○ Open Access. ๑ 2018 Ya-Qian Liu et al., published by Sciendo. (c) BY-NC-ND This work is licensed under the Creative Commons Attribution NonCommercial-NoDerivatives 4.0 License. that they can adapt and respond to these challenges. ${ }^{1}$ Self-directed learning is related to meta-cognition, motivation, and behavior with a positive attitude. ${ }^{2}$ It includes self-management, self-control, and desire for learning. ${ }^{3}$ Self-directed learning can be beneficial in providing nurses with the skills to seek, analyze, and apply theory to practice effectively. ${ }^{4}$ In consideration of its numerous 
benefits, self-directed learning is highly emphasized in nursing education and clinical circumstance and also deemed as an indispensable skill for learning and working in the 21 st century. ${ }^{5}$ Thus, self-directed learning is critical to enhance the clinical capacity of clinical nurses.

Researchers had confirmed that the flipped classroom (FC) had a positive effectiveness on self-directed learning and discussion skills. ${ }^{6}$ However, no systematic review has yet demonstrated the evidence for using the FC method to improve nursing students' self-directed learning. Many findings suggest that FCs could be used as an effective teaching method in promoting selfdirected learning..$^{7-9}$ In the study of Gagnon et al, blending learning with internet-based tutorials compared with traditional teaching methods introduced nursing research to nursing undergraduates. ${ }^{7}$ The results indicated that the blended-teaching method could much fit for nursing undergraduates, depending on their level of motivation and degree of readiness to engage in selfdirected learning. A Chinese study ${ }^{9}$ compared the "FC" teaching model design with traditional teaching models in the application of basic nursing scenarios through a non-random concurrent controlled trial. The result suggested that the "FC" teaching model could help nursing undergraduates promote self-learning ability. However, apparent inconsistency still remains. An experimental and comparative study conducted by Jahromi et al. showed insignificant differences between intervention and control groups. ${ }^{8}$ Tian also showed no significant increase in self-learning ability in the intervention group, but after controlling for age, the adjusted mean scores of the FC group were higher than those of the traditional group, the lecture group. ${ }^{9}$

During the nursing education process, the impact of the FC model on self-directed learning should be determined. The purpose of this meta-analysis was to systematically review and statistically summarize evidence of the effect of the FC teaching method on selfdirected learning and to provide clearer insights into the application of the FC teaching method in nursing education. Thus, this meta-analysis answers the following questions: what are the primary resources and research development of studies are in which the FC teaching method was used to improve self-directed learning in nursing education; how the quality of the included studies is; what is the effect of the FC teaching method is on development of self-directed learning in nursing education, and whether this evidence could be applied to guide nursing education.

Self-directed learning (SDL) is a teaching method that can be defined in terms of the quantity of responsibility accepted by learner's own learning and performance. ${ }^{10}$ In the views of nursing educators, self-directed learning has been defined in different implications, ${ }^{11-13}$ while the most common definition presented by Knowles is that self-directed learning is a process in which learners take action, with or without the assistance of others, in judging their learning requirements, discovering learning goals, identifying available learning resources to learn, choosing appropriate learning strategies and evaluating learning outcomes. ${ }^{14}$ Overall, self-directed learning in nursing has been identified with as having several stages, including assessing (readiness for self-direction, learning needs, material and human resources, and the learning environment), planning (interpreting self-directed learning), implementing, and evaluating. ${ }^{15}$

Many reviews of the literature revealed that a number of tools were used to measure self-directed learning ability, such as the Self-Directed Learning Readiness Scale (SDLRS), ${ }^{16}$ Self-Directed Learning Readiness Scale for Nursing Education (SDLRSNE), ${ }^{10}$ Self-Regulated Learning scale (SRL), ${ }^{17}$ Autonomous Learning Competencies scale (ALC), ${ }^{18}$ and the Competencies of Autonomous Learning of Nursing Students (CALNS). ${ }^{19}$ The SDLRS is a scale that was used to assess the degree to which people considered themselves as having the skills and attitude essential for self-directed learning. Many studies report that it has good reliability and validity, $8,16,20$ but several others cast on the cost and criticize its intent. ${ }^{16,21,22}$ This scale is a 41 -item questionnaire in five parts. It is based upon a Likert scale and consists of three sections: self-management, learning engagement, and self-control. The SDLRSNE was developed as an alternative to Gugliemino's (1997) SDLRS. The internal consistency of SDLRSNE and its subscales has been reported in several studies. ${ }^{7,23,24}$ This scale consists of three components: self-management (12 items; Cronbach's $\alpha=0.8$ ), self-control (15 items; Cronbach's $\alpha=$ 0.74), and desire for learning (13 items; Cronbach's $\alpha$ $=0.8$ ). Each item was assessed using a 5-point Likert scale, ranging from strongly disagree (1 point) to strongly agree (5 points). ${ }^{23}$ Furthermore, SRL, as developed by Zhang and $\mathrm{Li}^{17}{ }^{17}$ is a 30 -item scale with four subscales: learning motivation (eight items), self-learning ability (five items), self-management skills (eleven items), and information literacy (six items). The scale demonstrates favorable inter-item consistency and split-half reliability. ${ }^{17}$ Meanwhile, the internal consistency reliability of the $\mathrm{ALC}^{18}$ and the CALNS ${ }^{19}$ using the Delphi Report's consensus definition of self-directed learning ability was satisfactory.

As is well-known, traditional teaching models that provide a teacher-centered approach mean that students are not actively engaged in processing information, developing understanding, or applying knowledge into practice. ${ }^{6}$ However, the FC model, which provides a studentcentered approach, presents nursing students with the 
opportunity to enhance their self-directed learning, analytical skills, problem-solving abilities, and lifelong learning. ${ }^{25}$ Moreover, this model integrates cooperation, team learning and active learning, which are crucial strategies for students to provide the essential skills and abilities to work in a cross-disciplinary practice environment. ${ }^{26,27}$ Through the FC process, nursing students receive the same content as traditional classroom in the course setting, but the instructors' techniques are different as black and white: face to face lectures; homework before class; using case studies, laboratories, and games; discussing in groups, and simulation-based learning. ${ }^{28}$ Thus, nursing students were responsible for their own education and strengthened their autonomy of their studies.

The sudden increase in FCs conforms the studentcentered requirements of higher education. ${ }^{29}$ Although the FC model was taken up in other disciplines, there is a lack of evidence about the effect in the nursing curricula. Therefore, this meta-analysis review aims to fill this gap in examining the best evidence of the effectiveness of the FC as a burgeoning teaching model on the development of self-directed learning in nursing education.

\section{Methods}

\subsection{Search strategy}

A systematic search was conducted of literature in electronic databases without geographical restriction. The primary sources included PubMed, Embase, Web of Science, Cumulative Index to Nursing and Allied Health Literature (CINAHL), Cochrane Central Register of Controlled Trials (CENTRAL), Wanfang Data, China National Knowledge Infrastructure (CNKI), and Chinese Science and Technology Periodical Database (VIP). The search was restricted from inception to June 2017 with the papers published in English and Chinese. The search terms were finally identified according to the relevant literature and reviews in Cochrane Library and
Joanna Briggs Institute (JBI) Library, by researching and summarizing the titles, abstracts, and keywords. The $\mathrm{MeSH}$ terms and keywords of searching were used separately or in assembly. The search strategy for PubMed is shown in Table 1.

All results were downloaded as duplicates into Endnote $\mathrm{X} 7$ for checking and removing into different lines in accordance with the titles, abstracts, and keywords. The potential papers in the references were checked to identify appropriate studies satisfying the inclusion criteria that may have been excluded by the search strategy. Additionally, full texts of any indefinite papers were downloaded for review.

\subsection{Inclusion and exclusion criteria}

Two reviewers screened the titles and abstracts of all articles in the initial broad searching. Articles were selected for inclusion if: (1) a randomized controlled trial (RCT) or non-RCT comparative study; (2) subjects included higher vocational students, undergraduates, and postgraduates; (3) they used flipped teaching as an intervention; (4) include the outcome indicators for self-directed learning; and (5) reported the sample size of the subjects, the mean difference with $95 \% \mathrm{Cl}$ of selfdirected learning scores. Articles were excluded if: (1) the same group of subjects also received other teaching methods; (2) without complete data; and (3) duplicate articles.

\subsection{Data extraction}

Two of the authors extracted and summarized independently the data from the included studies. Any disagreement was resolved by the adjudicative senior authors. The data were extracted in a pre-designed coding manual: the first authors, publication years, countries, study designs, subjects, sample size (intervention group and control group), curriculum, teaching model in

\footnotetext{
\#1 "flipped classroom" OR "flipped teaching" OR "flipped classroom teaching method" OR "flipped model" OR "the flipped class model" OR "reverse classroom teaching" OR "reverse teaching" OR "contra-traditional teaching approach" OR flip*OR "active learning" OR "blended learning" OR "problem-based learning"[Title/Abstract]

\#2 "Education, Nursing"[Mesh]

\#3 nurs* OR students nurs* OR education nurs* OR "nurs* education research" OR nursing[Title/Abstract]

\#4 \#2 OR \#3

\#5 "self-management" OR "desire for learning" OR "self-control" OR "self-regulated learning" OR "Independent learning capability" OR "autonomous learning ability" OR "Self-learning ability" OR "Self-direct learning" OR "Learner Autonomy" OR "self-learning readiness" [Title/ Abstract]

\#6 "randomized controlled trial" OR "random*" OR "RCT"

\#7 \#1 AND \#4 AND \#5 AND \#6
}

Table 1. Search strategies. Note: MeSH: Medical Subject Heading. 
intervention and control groups, duration of intervention, outcome, and outcome measures.

\subsection{Quality appraisal}

The methodological quality of the studies was assessed as three levels including low bias, uncertain, and high bias by the authority of the Cochrane Handbook for Systematic Reviews of Intervention. ${ }^{30}$ The list of sevenitems checked on the Cochrane Handbook is as follows: adequacy of the generation of the allocation sequence, concealment of allocation, blinding participants and personnel, blinding outcome assessment, incomplete outcome data, selective outcome reporting, and other sources of bias. The assessment was independently conducted by two reviewers, and all disparities between them were resolved by consensus.

\subsection{Statistical analysis}

A meta-analysis of RCTs and quasi-experimental studies using Review Manager (RevMan) 5.3 software was conducted to explore differences between the intervention group and control group. The main strategy was to abstract and analyze the self-directing learning scores from different trials. Since the continuous outcomes which were expressed as a mean value and standard deviation measured by the scales, the standardized mean difference (SMD) of continuous outcomes was calculated from different scales and weighted mean differences (WMDs) was analyzed from the same scales. Chi-squared test and $l^{2}$ value were applied to estimate the influence of heterogeneity on the results of this metaanalysis. According to the Cochrane review guidelines, the random-effects models would be selected if severe heterogeneity was shown at $R^{2}>50 \%$; otherwise, the fixed-effects models would be chosen. Moreover, sensitivity analysis was performed by deleting each study individually to appraise the consistency and quality of the results. Subgroup analysis was performed according to the scale dimension.

\section{Results}

\subsection{The search results}

The flow diagram about the process of including and excluding studies is shown in Fig. 1. The search yielded 724 relevant articles, and 462 duplicated records were excluded. A further 413 studies were excluded after screening by reading the titles and abstracts. The full texts of 49 studies were assessed, while 29 studies were excluded due to following reasons: 23 articles contained outcome variables different from the interest of this review, two articles were reported in Korean language, and four articles were self-controlled studies. Of the 20 studies eligible for qualitative analysis, 12 were included in this meta-analysis

\subsection{Description of included studies}

A description of the included studies is listed in Table 2. Twelve articles were included in the meta-analysis, and their total sample size was 1440 persons (755 in the intervention group and 685 in the control group). Ten of the included studies were completed in China and written in Chinese. ${ }^{9,31-39}$ One study was carried out in $\mathrm{Canada}^{7}$ and one in Iran, ${ }^{8}$ both were written in English. The subjects of the included studies were nursing students. Among them, the participants of six studies were nursing undergraduates and those remaining were higher vocational nursing students. The sample size of included individual studies ranged from 30 to 193 participants, and the pooled sample size was 1440 (intervention group $=755$ and control group $=685$ ). Four studies were performed in nursing practice courses, and the others were medical theoretical lessons. The duration of intervention varied greatly, ranging from two periods to two semesters.

The scales for measuring outcomes of the included studies were as follows: SRL, ${ }^{9,31,38-40} \mathrm{ALC},{ }^{32,34}$ SDLRS, ${ }^{8}$ SDLRSNE, ${ }^{7}$ and some specially designed scales. ${ }^{33,36,41}$ The specially designed scales created by Chinese authors were not universally applied due to regional restrictions.

\subsection{The quality of included studies}

Fig. 2 and Fig. 3 show the differences in the risk of bias among the studies. Each included study was evaluated as a bias of high risk, low risk or unclear by using the assessment standards mentioned earlier. Of 12 included studies, the quality rating of one was $A$ and of the others was B. Of nine RCTs and three quasi-experimental studies, four reported the random sequence generation in details, while three articles ${ }^{32,36,37}$ were concealed by drawing lots from a sealed box and one paper ${ }^{7}$ was a computerized random number generator. The allocation sequence of three studies ${ }^{8,33,35}$ was assigned by convenience sampling or the preference of the researchers, in which students were divided into experimental or control groups. Thus, ten studies did not report allocation concealment, which may cause selection bias. And for the remaining no details were mentioned. Considering the feature of the intervention, blinding of nursing students and teachers to the intervention is impracticable. However, ten studies reported the same teacher, course 


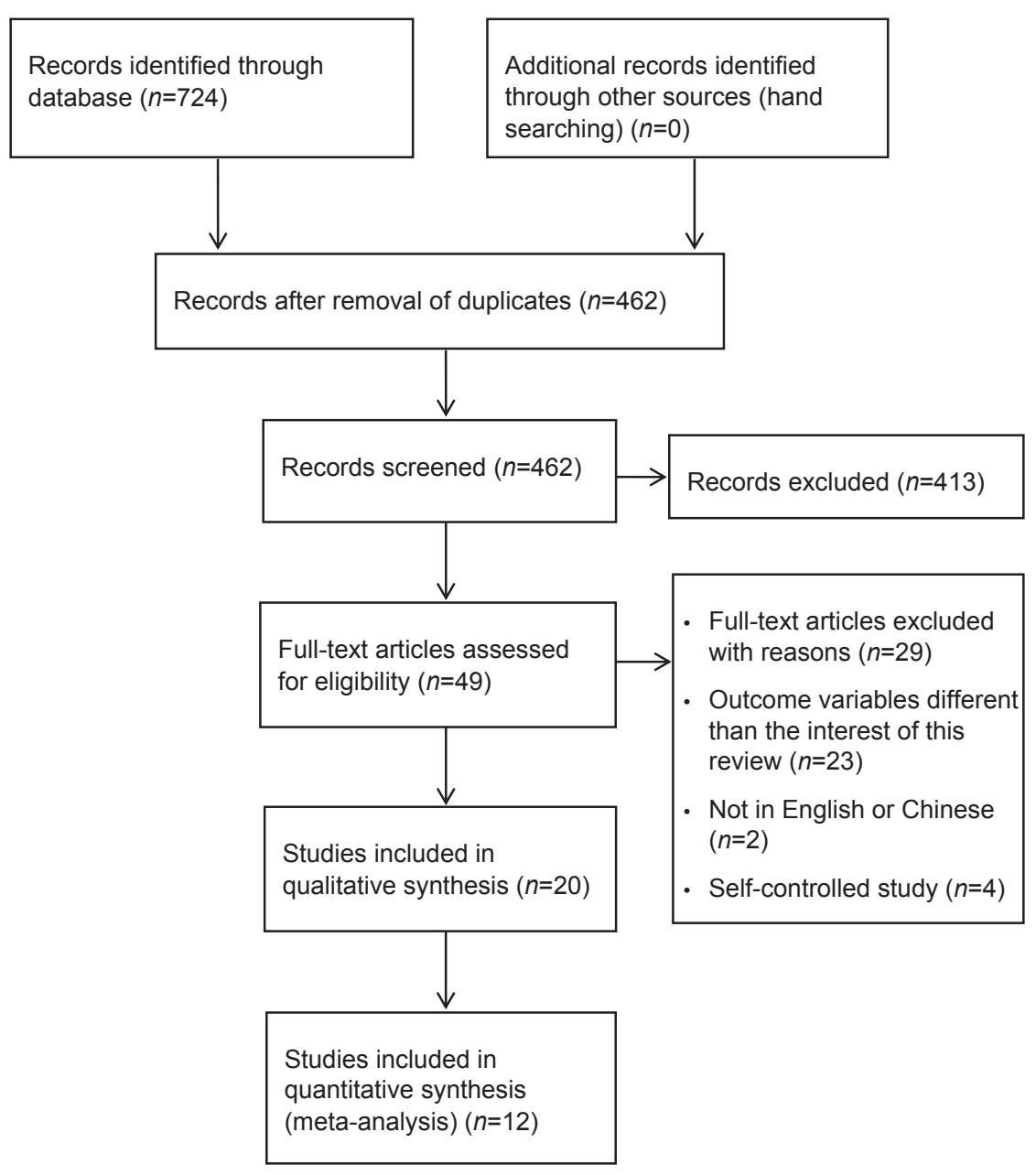

Figure 1. Flow diagram of included and excluded studies.

duration, and teaching schedule in experimental or control groups. This was not likely to be influenced by lack of blinding procedures and awarded adequate for blinding. In addition, all studies described the results to prevent reporting bias. Beyond that, all studies reported that there were no significant difference between experimental and control groups about baseline data, which included age, sexuality, and academic records. At last, all included studies were free from "other bias" as defined in the Cochrane Handbook.

\subsection{The result of meta-analysis}

\subsubsection{Overall self-directed learning scores}

Fig. 4 shows the overall self-directed learning scores of different scales. Twelve studies in meta-analysis involving 1440 nursing students (intervention group = 755 , control group $=685$ ) were provided data for pooling to show the effect of FC on self-directed learning.
$\mathrm{One}^{7}$ reported three times of outcome data on three different SDLR levels at baseline (low, medium, and high), and therefore, 14 studies of outcome data were reported in the meta-analysis. The heterogeneity test showed obviously significant heterogeneity between the included studies using different scales $\left(R^{2}=95 \%\right)$ and indicated that the FC had a significant effect on self-directed learning ability $(\mathrm{SMD}=1.18,95 \% \mathrm{Cl}$ $[0.71,1.66], P<0.00001)$. Considering that the duration of intervention for each included study was different, subgroup analysis was used to explore the source of heterogeneity source.

The results of the subgroup analysis conducted according to the duration of interventions were as follows: Jahromi et al. ${ }^{8}$ and Tian et al. ${ }^{37}$ showed no statistically significant difference in nursing students' overall self-directed learning scores between the intervention and control groups, while others showed statistically significant differences. Each subgroup analysis indicated a significant effect on the different 


\begin{tabular}{|c|c|c|c|c|c|c|c|c|}
\hline Author & Country & Design & Subject & $\begin{array}{l}\text { Sample } \\
\text { size }\end{array}$ & Curriculum & Intervention (duration) & Control & $\begin{array}{l}\text { Measurement } \\
\text { of outcomes }\end{array}$ \\
\hline Wang $^{38}$ & China & RCT & $\begin{array}{l}\text { High vocational } \\
\text { nursing students }\end{array}$ & $\begin{array}{l}E: 50 \\
C: 51\end{array}$ & $\begin{array}{l}\text { Medical } \\
\text { nursing } \\
\text { experiment } \\
\text { teaching }\end{array}$ & $\begin{array}{l}\text { FC: } \\
\text { 1. Pre-class individual } \\
\text { instruction } \\
\text { 2. In-class group } \\
\text { interactive activities } \\
\text { (one semester) }\end{array}$ & $\begin{array}{l}\text { Traditional } \\
\text { teaching }\end{array}$ & $\mathrm{SRL}$ \\
\hline $\begin{array}{l}\text { Jing and } \\
\mathrm{Li}^{34}\end{array}$ & China & $\mathrm{RCT}$ & $\begin{array}{l}\text { High vocational } \\
\text { nursing students }\end{array}$ & $\begin{array}{l}E: 50 \\
C: 52\end{array}$ & $\begin{array}{l}\text { Assessment } \\
\text { of technical } \\
\text { symptoms } \\
\text { of health } \\
\text { assessment }\end{array}$ & $\begin{array}{l}\text { OSCE and FC: } \\
\text { 1. Pre-class individual } \\
\text { instruction } \\
\text { 2. In-class group } \\
\text { interactive activities with } \\
\text { OSCE (one semester) }\end{array}$ & $\begin{array}{l}\text { Traditional } \\
\text { teaching }\end{array}$ & ALC \\
\hline $\begin{array}{l}\text { Tian } \\
\text { et al. }{ }^{37}\end{array}$ & China & RCT & $\begin{array}{l}\text { Nursing } \\
\text { undergraduate } \\
\text { intern }\end{array}$ & $\begin{array}{l}E: 32 \\
C: 32\end{array}$ & $\begin{array}{l}\text { Geriatric } \\
\text { nursing }\end{array}$ & $\begin{array}{l}\text { FC: } \\
\text { 1. Pre-class individual } \\
\text { instruction } \\
\text { 2. In-class group } \\
\text { interactive activities } \\
\text { 3. After-class self- } \\
\text { reflection and evaluation } \\
\text { (one semester) }\end{array}$ & $\begin{array}{l}\text { Traditional } \\
\text { teaching }\end{array}$ & $\mathrm{SRL}$ \\
\hline $\begin{array}{l}\text { Chen } \\
\text { et al. }{ }^{31}\end{array}$ & China & $\mathrm{RCT}$ & $\begin{array}{l}\text { Nursing } \\
\text { undergraduate } \\
\text { intern }\end{array}$ & $\begin{array}{l}E: 36 \\
C: 36\end{array}$ & $\begin{array}{l}\text { Emergency } \\
\text { intensive care }\end{array}$ & $\begin{array}{l}\text { BL and FC: } \\
\text { 1. Pre-class individual } \\
\text { instruction } \\
\text { 2. In-class group } \\
\text { interactive activities with } \\
\text { OSCE ( } 2 \text { periods) }\end{array}$ & $\begin{array}{l}\text { Traditional } \\
\text { teaching }\end{array}$ & $\mathrm{SRL}$ \\
\hline $\begin{array}{l}\text { Song } \\
\text { et al. }^{36}\end{array}$ & China & $\mathrm{RCT}$ & $\begin{array}{l}\text { Nursing } \\
\text { undergraduate } \\
\text { intern }\end{array}$ & $\begin{array}{l}E: 30 \\
C: 30\end{array}$ & $\begin{array}{l}\text { Basic } \\
\text { nursing, } \\
\text { experimental } \\
\text { teaching }\end{array}$ & $\begin{array}{l}\text { FC: } \\
\text { 1. Pre-class individual } \\
\text { instruction } \\
\text { 2. In-class group } \\
\text { interactive activities; } \\
\text { 3. After-class self- } \\
\text { reflection and evaluation } \\
\text { (4 periods) }\end{array}$ & $\begin{array}{l}\text { Traditional } \\
\text { teaching }\end{array}$ & $\begin{array}{l}\text { Specially } \\
\text { designed }\end{array}$ \\
\hline Deng $^{32}$ & China & $\mathrm{RCT}$ & $\begin{array}{l}\text { Nursing } \\
\text { undergraduate } \\
\text { intern }\end{array}$ & $\begin{array}{l}E: 34 \\
C: 32\end{array}$ & $\begin{array}{l}\text { Introduction } \\
\text { of nursing } \\
\text { science }\end{array}$ & $\begin{array}{l}\text { FC: } \\
\text { 1. Pre-class individual } \\
\text { instruction } \\
\text { 2. In-class group } \\
\text { interactive activities } \\
\text { 3. After-class self- } \\
\text { reflection and evaluation } \\
\text { (one semester) }\end{array}$ & $\begin{array}{l}\text { Traditional } \\
\text { teaching }\end{array}$ & ALC \\
\hline $\begin{array}{l}\text { Zong } \\
\text { et al. }{ }^{39}\end{array}$ & China & RCT & $\begin{array}{l}\text { High vocational } \\
\text { nursing students }\end{array}$ & $\begin{array}{l}E: 101 \\
C: 100\end{array}$ & $\begin{array}{l}\text { Basic } \\
\text { nursing, } \\
\text { experimental } \\
\text { teaching }\end{array}$ & $\begin{array}{l}\text { FC with Wechat: } \\
\text { 1. Pre-class individual } \\
\text { instruction } \\
\text { 2. In-class group } \\
\text { interactive activities } \\
\text { 3. After-class self- } \\
\text { reflection and evaluation } \\
\text { (two semesters) }\end{array}$ & $\begin{array}{l}\text { Traditional } \\
\text { teaching }\end{array}$ & $\mathrm{SRL}$ \\
\hline $\begin{array}{l}\text { Gagnon } \\
\text { et al. }{ }^{7}\end{array}$ & Canada & RCT & $\begin{array}{l}\text { Nursing } \\
\text { undergraduates }\end{array}$ & $\begin{array}{l}E: 56 \\
C: 56\end{array}$ & $\begin{array}{l}\text { Nursing } \\
\text { research }\end{array}$ & $\begin{array}{l}\text { BL with internet-based } \\
\text { tutorials: } \\
\text { 1. Pre-class individual } \\
\text { instruction } \\
\text { 2. In-class group } \\
\text { interactive activities } \\
\text { 3. After-class self- } \\
\text { reflection and evaluation } \\
\text { (13 periods) }\end{array}$ & $\begin{array}{l}\text { Traditional } \\
\text { teaching }\end{array}$ & SDLRSNE \\
\hline $\operatorname{Tian}^{9}$ & China & $\begin{array}{l}\text { Quasi- } \\
\text { experiment }\end{array}$ & $\begin{array}{l}\text { Nursing } \\
\text { undergraduates }\end{array}$ & $\begin{array}{l}E: 193 \\
C: 129\end{array}$ & $\begin{array}{l}\text { Basic } \\
\text { nursing, } \\
\text { experimental } \\
\text { teaching }\end{array}$ & $\begin{array}{l}\text { FC: } \\
\text { 1. Pre-class individual } \\
\text { instruction } \\
\text { 2. In-class group } \\
\text { interactive activities } \\
\text { 3. After-class self- } \\
\text { reflection and evaluation } \\
\text { (one semester) }\end{array}$ & $\begin{array}{l}\text { Traditional } \\
\text { teaching }\end{array}$ & SRL \\
\hline
\end{tabular}

Table 2. Characteristics of included studies. 


\begin{tabular}{|c|c|c|c|c|c|c|c|c|}
\hline Author & Country & Design & Subject & $\begin{array}{l}\text { Sample } \\
\text { size }\end{array}$ & Curriculum & Intervention (duration) & Control & $\begin{array}{l}\text { Measurement } \\
\text { of outcomes }\end{array}$ \\
\hline $\begin{array}{l}\text { Liu } \\
\text { et al. }{ }^{35}\end{array}$ & China & $\begin{array}{l}\text { Quasi- } \\
\text { experiment }\end{array}$ & $\begin{array}{l}\text { Nursing } \\
\text { undergraduates }\end{array}$ & $\begin{array}{l}E: 31 \\
C: 30\end{array}$ & $\begin{array}{l}\text { Optional } \\
\text { courses for } \\
\text { rehabilitation } \\
\text { nursing }\end{array}$ & $\begin{array}{l}\text { FC: } \\
\text { 1. Pre-class individual } \\
\text { instruction } \\
\text { 2. In-class group } \\
\text { interactive activities } \\
\text { 3. After-class self- } \\
\text { reflection and evaluation } \\
\text { (one semester) }\end{array}$ & $\begin{array}{l}\text { Traditional } \\
\text { teaching }\end{array}$ & SRL \\
\hline $\mathrm{Hui}^{33}$ & China & $\begin{array}{l}\text { Quasi- } \\
\text { experiment }\end{array}$ & $\begin{array}{l}\text { High vocational } \\
\text { nursing students }\end{array}$ & $\begin{array}{l}E: 107 \\
C: 107\end{array}$ & $\begin{array}{l}\text { Psychiatric } \\
\text { nursing }\end{array}$ & $\begin{array}{l}\text { FC: } \\
\text { 1. Pre-class individual } \\
\text { instruction } \\
\text { 2. In-class group } \\
\text { interactive activities } \\
\text { 3. After-class self- } \\
\text { reflection and evaluation } \\
\text { (one semester) }\end{array}$ & $\begin{array}{l}\text { Traditional } \\
\text { teaching }\end{array}$ & CALNS \\
\hline $\begin{array}{l}\text { Jahromi } \\
\text { et al. }^{8}\end{array}$ & Iran & $\begin{array}{l}\text { Quasi- } \\
\text { experiment }\end{array}$ & $\begin{array}{l}\text { Nursing } \\
\text { undergraduates }\end{array}$ & $\begin{array}{l}E: 39 \\
C: 38\end{array}$ & $\begin{array}{l}\text { Mental } \\
\text { health and } \\
\text { psychiatric } \\
\text { disorders }\end{array}$ & $\begin{array}{l}\text { TBL: } \\
\text { 1. Readiness lesson by } \\
\text { teacher } \\
\text { 2. Readiness assurance } \\
\text { test } \\
\text { 3. Application as a team } \\
\text { (two semesters) }\end{array}$ & $\begin{array}{l}\text { Web quest } \\
\text { teaching }\end{array}$ & SDLRS \\
\hline
\end{tabular}

Table 2. (Continued).

Note: ALC: Autonomous Learning Competencies scale; BL: blending learning; CALNS: Competencies of Autonomous Learning of Nursing Students; FC: flipped classroom; TBL: team-based learning; OSCE: Objective Structured Clinical Examination; RCT: randomized controlled trial; SDLRS: Self-Directed Learning Readiness Scale; SDLRSNE: SelfDirected Learning Readiness Scale for Nursing Education; SRL: Self-Regulated Learning scale.

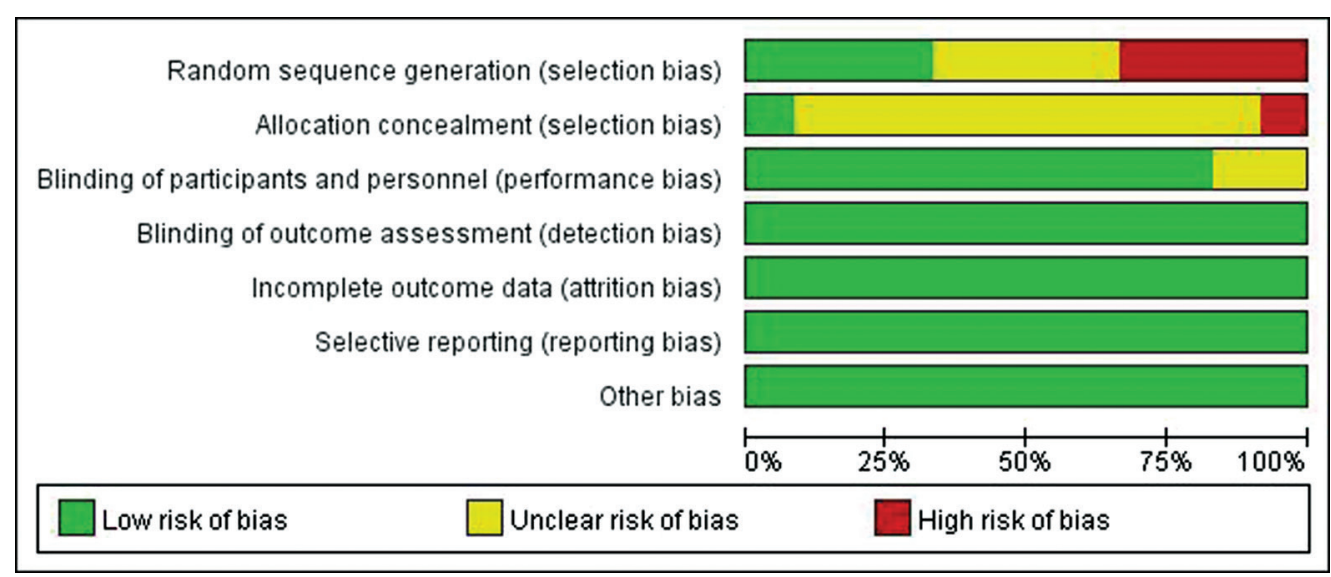

Figure 2. Risk of bias graph.

duration of intervention in two to four periods (SMD = $0.87,95 \% \mathrm{Cl}[0.20,1.55], P=0.01)$, half semester (SMD $=3.20,95 \% \mathrm{Cl}[2.86,3.54], P<0.00001)$, one semester (SMD $=0.68,95 \% \mathrm{Cl}[0.45,0.91], P<0.00001)$, and two semesters (SMD $=0.40,95 \% \mathrm{Cl}[0.23,0.58], P<$ $0.00001)$.

\subsubsection{Self-directed learning measured by SRL}

Five studies including 618 subjects, which were measured by the SRL scale, provided data for pooling to show the effect of the FC on self-directed learning ability. Heterogeneity analysis showed a significant heterogeneity among the included studies $\left(I^{2}=65 \%\right)$ (Fig. 5). Thus, meta-analysis based on the random-effects model and subgroup analysis was conducted according to the four dimensions of the scale. The results showed a more significant effect in the intervention group than that in the control group on the domains of learning motivation $(\mathrm{SMD}=2.05,95 \% \mathrm{Cl}[0.96,3.13], P=0.0002)$, self-learning ability (SMD $=1.89,95 \% \mathrm{Cl}[1.34,2.45]$, $P<0.00001)$, self-management skills $(\mathrm{SMD}=2.69,95 \%$ 


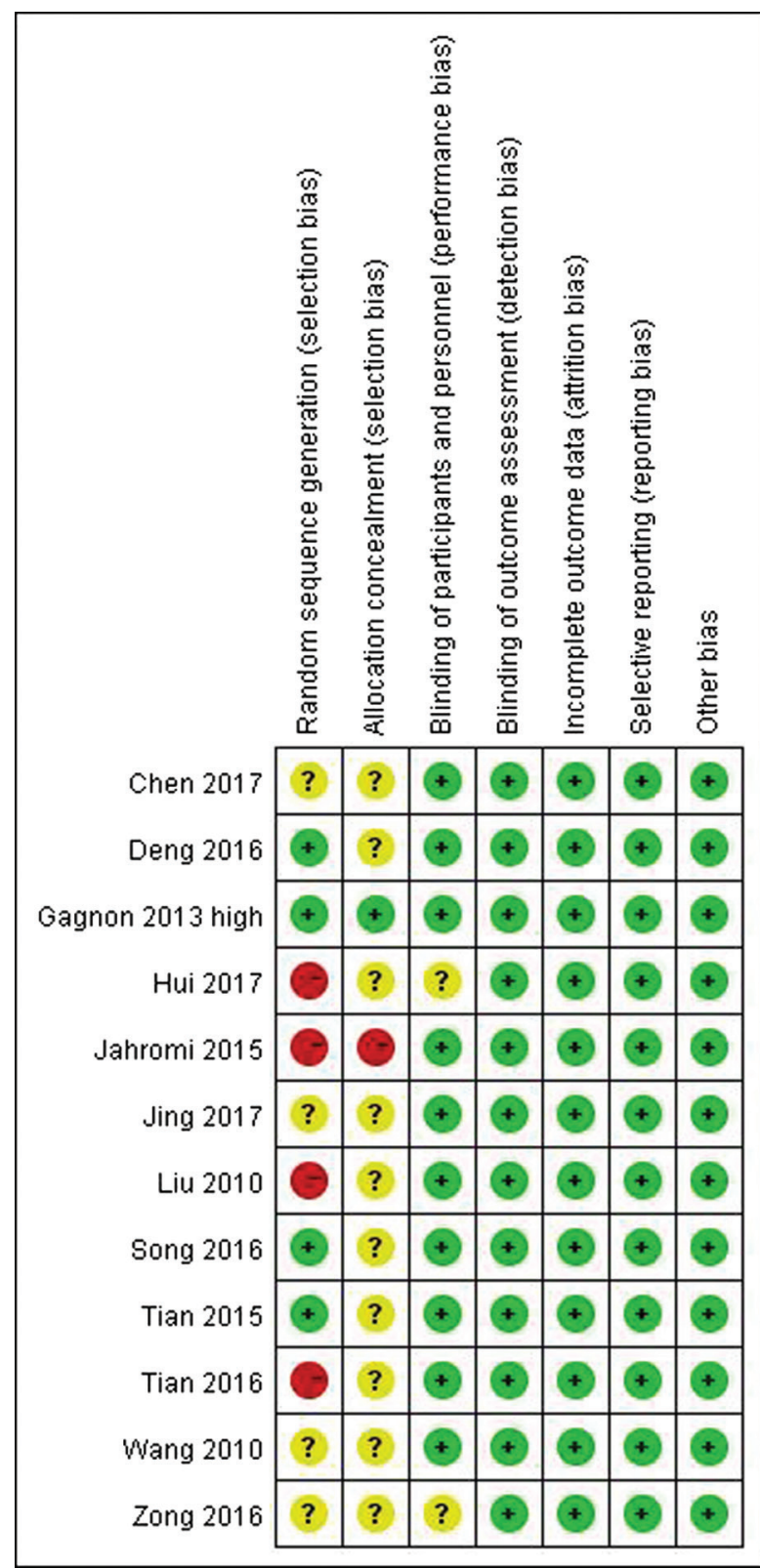

Figure 3. Summary of risk of bias assessment.

$\mathrm{Cl}[1.68,3.70], P<0.00001)$, and information literacy $(\mathrm{SMD}=0.93,95 \% \mathrm{Cl}[0.16,1.70], P=0.02)$.

\subsubsection{Self-directed learning measured by other scales}

Of the five studies included, three used different scales and one was measured twice by the ALC scale and once before and after once the intervention. However, the combined results had a significant heterogeneity, but no obvious heterogeneity source was found. Therefore, only descriptive analysis was conducted. Findings of $\mathrm{FC}$ effects in other scales are summarized in Table 3.
In the study of Deng ${ }^{32}$, self-directed learning ability overall score of ALC scale was assessed. The pooled effect sizes for it favored intervention group on selfmanagement ability $(\mathrm{SMD}=0.79,95 \% \mathrm{Cl}[0.43,1.16]$, $P<0.00001)$, self-learning ability $(\mathrm{SMD}=0.65,95 \% \mathrm{Cl}$ $[0.28,1.01], P=0.0005)$, and information literacy (SMD $=0.82,95 \% \mathrm{Cl}[0.44,1.20], P<0.0001)$.

Inversely, Jahromi et al. ${ }^{8}$ reported the subscale scores of the SDLRS. The pooled effect size for selfengagement $(\mathrm{SMD}=0.01,95 \% \mathrm{Cl}[-0.43,0.46]$, $P=0.95)$ and self-management $(\mathrm{SMD}=0.11,95 \% \mathrm{Cl}$ $[-0.34,0.55], P=0.64$ ) favored the control group, and this indicated that the scores were higher in the control group than those in the experimental group. However, self-control $(\mathrm{SMD}=-0.79,95 \% \mathrm{Cl}[-1.25,-0.33]$, $P=0.0009$ ) showed a significant difference between the two groups.

Hui ${ }^{33}$ reported the scores of three levels of the CALNS on self-directed learning ability. The pooled effect sizes favored the intervention group on self-learning ability $(\mathrm{SMD}=2.19,95 \% \mathrm{Cl}[1.08,3.30], P=0.0001)$ and information literacy $(\mathrm{SMD}=3.33,95 \% \mathrm{Cl}[1.66,5.00]$, $P<0.0001$ ), while the scores of self-management ability $(\mathrm{SMD}=1.23,95 \% \mathrm{Cl}[-0.28,2.74], P=0.11)$ showed no significant difference between the two groups.

\section{Discussion}

\subsection{Finding summaries}

In accordance with the result of searching eight databases, this is the first meta-analysis about the impact of the FC method on self-directed learning of nursing students. This systematic review and meta-analysis examined how the FC improved the self-directed learning of nursing graduates and provided evidence supporting the effectiveness of this emerging teaching model on self-directed learning in nursing education.

There are several problems concerning methodological quality of included studies in the assessment process. Most comparative studies were limited by the random allocation of the intervention and control groups descripted on the standard of Cochrane Collaboration for Systematic Reviews of Interventions. Many studies were lacking adequacy of the random sequence generation and allocation concealment, which caused greater selection bias. Owing to no description of whether nursing students in experimental and control groups used the same teaching resources, such as teaching platforms and teachers, curriculum content, and duration, some studies did not record adequate details about the blinding of participants and personnel. However, data collection by 


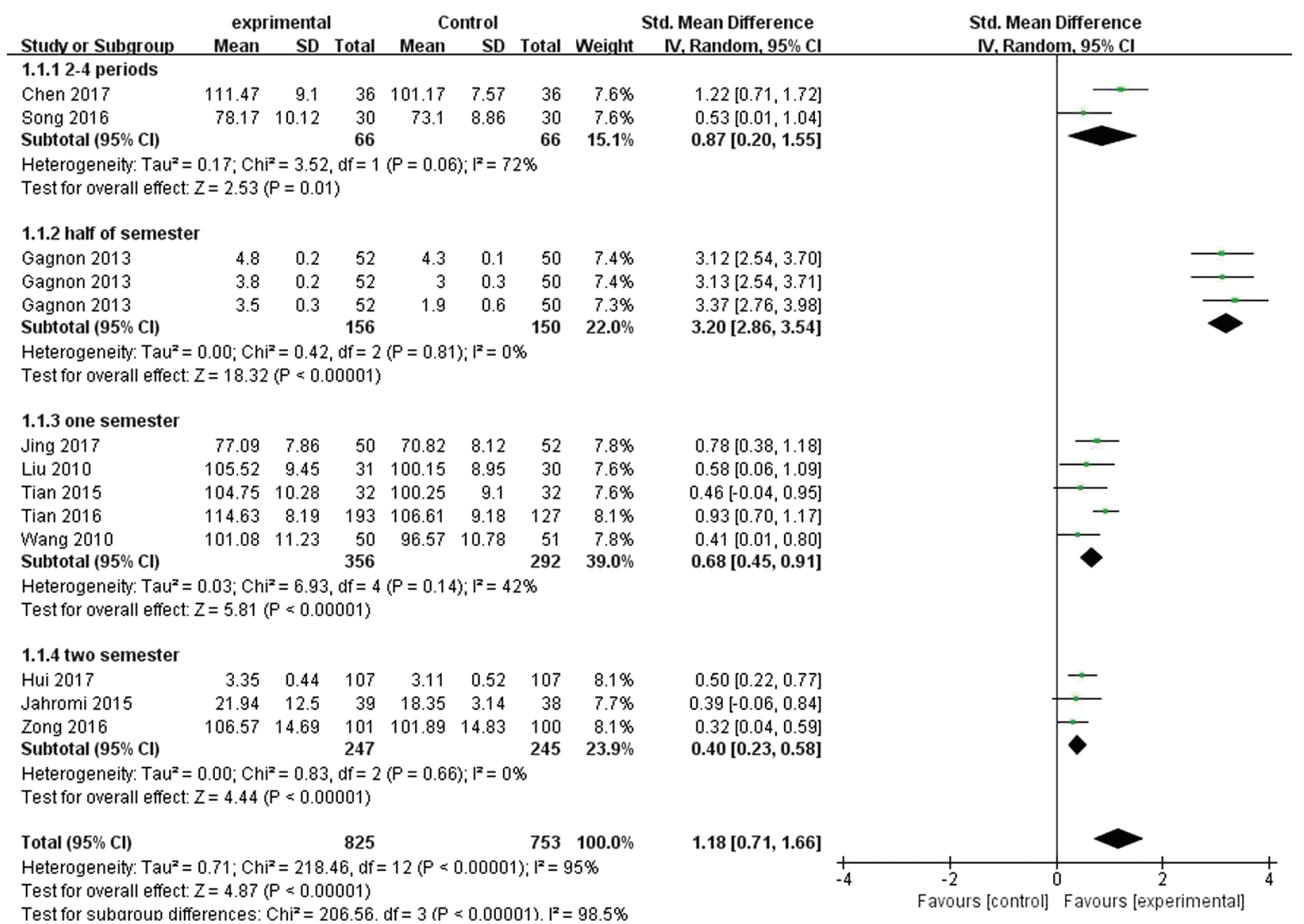

Figure 4. Forest plot of overall self-directed learning scores after using FC compared with traditional lectures.

the teachers who were directly in teaching may be not feasible. Questionnaires were released together by the teachers at the end of the course and recovered after students have anonymously filled out.

The FC teaching model intervention of the included studies was conducted over differing lengths of time, from two periods to two semesters. Thus, the results of subgroup analysis according to the duration of intervention showed that all students in the experimental group from two periods to two semesters had higher overall self-directed learning scores. Heterogeneity of the half semester and two semester subgroups was zero percent, which meant homogeneity and the result of the included studies were reliable. Considering the few studies measuring the outcomes for two to four periods of intervention, more researches are needed to confirm the impact of the duration of FC teaching on selfdirected learning development.

Among multifarious scales used to measure the effect of the FC teaching method on self-directed learning in this review, the SRL scale was the most frequently applied. Subgroup analysis showed that students in the FC had more active self-directed learning performance and motivation, self-learning ability, self-management skills, and information literacy compared with those in the traditional teaching. The FC teaching model was beneficial to learning motivation, because it was an internal power that could directly encourage nursing students to learn and an inward requirement that could strongly stimulate them to learn. The FC teaching model was of benefit to self-learning ability, because it helped students to adjust their psychological activity process of self-awareness, self-evaluation, self-development, selfeducation, and self-control during the course of learning. Higher scores in self-management skills reflected that learners in the FC could communicate with other classmates more positively and actively, cooperate with each other more harmoniously, and more willingly seek for help in the face of difficulties and obstacles. The reason might be that students must work at their own pace to master per-determined material with little or no help from an instructor. ${ }^{42}$ The FC teaching model was also beneficial to information literacy, because it improved the ability of nursing students to seek relevant information for themselves and evaluate how to utilize learning resources better. ${ }^{6}$ The pooled effect size for self-directed learning assessed by the SRL scale revealed that the FC was superior to the control group in the training of self-directed learning skills. According to the sensitivity analyses, the result is extremely stable. 


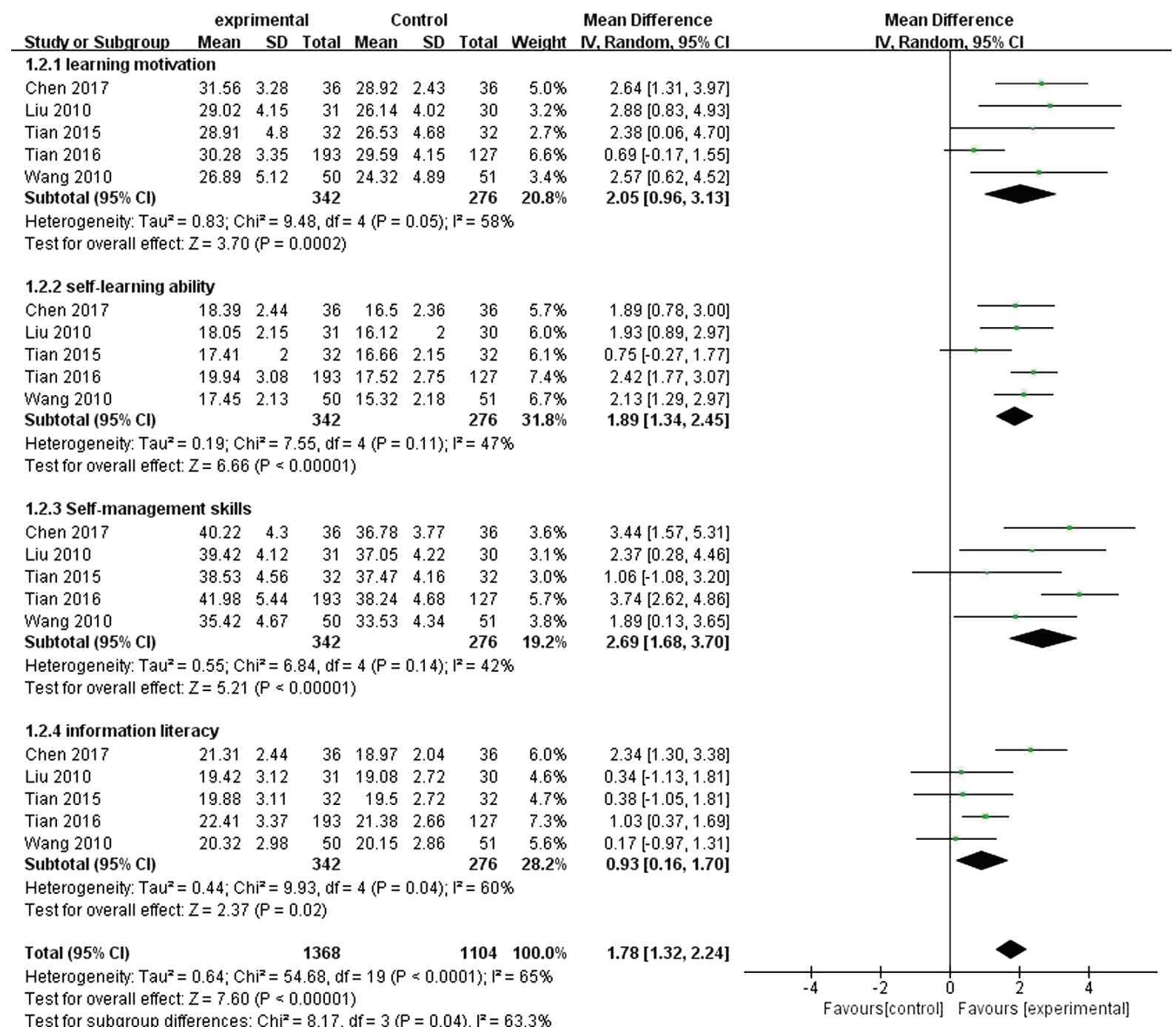

Figure 5. Forest plot of subscale scores measured by SRL.

Through the implementation of FC teaching, nursing students could acquire skills on how to apply information and resource and build capabilities and competencies by themselves rather than simply gain knowledge from books. ${ }^{43}$ In addition to this, the chop and change fantasticality characteristic of nursing work demanded current nurses be equipped with problem-solving, critical thinking, and information literacy off their own bat. More specifically, the cultivation plan of $\mathrm{FC}$ teaching better satisfied the above requirements by way of various learning activities serving as a datum line for the FC teaching design, including mini-lectures, self-learning resources, and debates/discussion. ${ }^{6}$ Conversely, individual students in traditional lecture-based classrooms were less motivated to study by autonomous learning. Acting as empty vessels absorbing information passively, they did not energetically participate in processing learning information, developing further understanding, or translating monotonous knowledge into practice. ${ }^{44}$ Therefore, the traditional classroom was not beneficial to explore initiative and self-directed learning.

\subsection{Strengths and limitations}

In this systematic review and meta-analysis, there were several aspects worth strengthening as follows: a more rigorous and comprehensive search strategy was developed by the authors, who received training on professional evidence-based courses, which broadly included the $\mathrm{MeSH}$ and keywords of FC, self-directed learning, 


\begin{tabular}{|c|c|c|c|c|}
\hline Outcomes & Trials & Sample size (EG/CG) & Intervention effect size $(\mathrm{Cl})$ & P-value of effect \\
\hline \multicolumn{5}{|l|}{$A L C$} \\
\hline Self-management ability & Deng $^{32}$ & $66(34 / 32)$ & $1.51[0.96,2.06]$ & $<0.00001$ \\
\hline Self-learning ability & Deng $^{32}$ & $66(34 / 32)$ & $1.56[1.00,2.11]$ & $<0.00001$ \\
\hline Information literacy & Deng $^{32}$ & $66(34 / 32)$ & $2.26[1.63,2.89]$ & $<0.00001$ \\
\hline \multicolumn{5}{|l|}{ CALNS } \\
\hline Self-management ability & $\mathrm{Hui}^{33}$ & $214(107 / 107)$ & $1.23[-0.28,2.74]$ & 0.11 \\
\hline Self-learning ability & $\mathrm{Hui}^{33}$ & $214(107 / 107)$ & $2.19[1.08,3.30]$ & 0.0001 \\
\hline Information literacy & $\mathrm{Hui}^{33}$ & $214(107 / 107)$ & $3.33[1.66,5.00]$ & $<0.0001$ \\
\hline \multicolumn{5}{|l|}{ SDLRS } \\
\hline Self-control ability & Jahromi et al. ${ }^{8}$ & $77(39 / 38)$ & $-0.79[-1.25,-0.33]$ & 0.0009 \\
\hline Self-engagement ability & Jahromi et al. ${ }^{8}$ & $77(39 / 38)$ & $0.01[-0.43,0.46]$ & 0.95 \\
\hline Self-management ability & Jahromi et al. ${ }^{8}$ & $77(39 / 38)$ & $0.11[-0.34,0.55]$ & 0.64 \\
\hline
\end{tabular}

Table 3. Description of self-directed learning measured by other scales.

Note: EG: experiment group; CG: control group; ALC: Autonomous Learning Competencies scale; CALNS: Competencies of Autonomous Learning of Nursing Students; Cl: confidence interval; SDLRS: Self-Directed Learning Readiness Scale.

and nursing education; the research was conducted on eight databases, and as many relevant articles were retrieved as possible; the quality of the included studies was moderate, and the overall sample size was adequate; most of the included studies well reported low risk on attrition bias and reporting bias, so the result could reflect the true effect of the FC model.

Meanwhile, findings of this paper should be interpreted in line with the following limitations: first, some potential studies have been possibly missed although the retrieval process was extensive and inclusive. Second, this review was limited by the small number of nonRCT studies that met the inclusion and quality criteria. The selection and extraction stages should be assessed independently by four reviewers to mitigate limitations. Lastly, due to the limitations of the RCT study type, many included studies ascertained self-directed learning by a diversity of measuring tools. The result was that statistical data analysis could not be reliably performed.

\subsection{Implications for practice and future research}

Clinical nursing practice in a dynamic health care environment requires more than knowledge just gained from books. Clinical nurses must also demonstrate essential self-directed learning skills such as self-learning ability, self-management, and self-engagement. Developing self-directed learning skills was influenced by personality responsibility and individual characteristics. ${ }^{45}$
The evaluation of self-directed learning should focus on not only objective variables but also responsibility and characteristics. Whether the responsibility and characteristics of students were framed positively or negatively, it was often in keeping with the individuals' learning experience in the context of the FC. Improving self-directed learning ability is a lengthy process; it permeates into the periods of classroom teaching, internship, and clinical work. ${ }^{46}$ Furthermore, a comprehensive assessment system should be exploited to assess selfdirected learning.

\section{Conclusions}

This systematic review and meta-analysis provided specific evidence on adopting the FC teaching method to improve self-directed learning in nursing education. By using the SRL, ALC, SDLRS, and CALNS as surveying instruments for assessing self-directed learning, the result of the meta-analysis proved that $\mathrm{FC}$ teaching could enhance the self-directed learning, including learning motivation, self-learning ability, self-management skills, and information literacy. However, due to a bewildering diversity of measuring tools, future studies with uniform measurement tools and more RCTs are needed to draw conclusions from the current study.

\section{Conflicts of interest}

All contributing authors declare no conflicts of interest. 
1. Majumdar B. Empowerment through self-directed learning. Can Nurse. 1999;95:37-40.

2. Zimmerman BJ. Becoming a self-regulated learner: an overview. Theory Into Pract. 2002;41:64-70.

3. Fisher MJ, King J. The Self-Directed Learning Readiness Scale for nursing education revisited: a confirmatory factor analysis. Nurse Educ Today. 2010;30:44-48.

4. Lunyk-Child OI, Crooks D, Ellis PJ, Ofosu C, O'Mara L, Rideout E. Self-directed learning: faculty and student perceptions. J Nurs Educ. 2001;40:116-123.

5. Effeney G, Carroll A, Bahr N. Self-regulated learning: key strategies and their sources in a sample of adolescent males. Aust J Educ Dev Psych. 2013;13:58-74.

6. Ihm J, Choi H, Roh S. Flipped-learning course design and evaluation through student selfassessment in a predental science class. Korean $J$ Med Educ. 2017;29:93-100.

7. Gagnon MP, Gagnon J, Desmartis M, Njoya M. The impact of blended teaching on knowledge, satisfaction, and self-directed learning in nursing undergraduates: a randomized, controlled trial. Nurs Educ Perspect. 2013;34:377-382.

8. Jahromi ZB, Mosalanejad L, Rezaee R. The effect of web quest and team-based learning on students' self-regulation. J Adv Med Educ Prof. 2016;4:80-87.

9. Tian ZJ. Application of "Flipped Classroom" Teaching Mode in Experimental Teaching of "Basic Nursing”. Taiyuan: Shanxi Medical University; 2016 (in Chinese).

10. Fisher M, King J, Tague G. Development of a selfdirected learning readiness scale for nursing education. Nurse Educ Today. 2001;21:516-525.

11. Bartel EV. Initiating a self-directed learning program in the classroom. Education. 1971;91:247.

12. Iwasiw CL. The role of the teacher in self-directed learning. Nurse Educ Today. 1987;7:222-227.

13. Jayasinghe $\mathrm{S}$. Learner centred approaches in medical education: its relevance in developing countries. BMJ. 1999;318:1280.

14. Knowles MS. Self-Directed Learning: a Guide for Learners and Teachers. Chicago, IL: Follett Publishing; 1975.

15. Njie-Carr VP, Ludeman E, Lee MC, Dordunoo D, Trocky NM, Jenkins LS. An integrative review of flipped classroom teaching models in nursing education. J Prof Nurs. 2017;33:133-144.

16. Guglielmino L. Development of the self-directed learning readiness scale. dissertation abstracts international. 1977;38:64-64A.
17. Zhang XY, Li XH. Study on the development of selflearning ability evaluation tools for nursing students. Nurs Res. 2009;23:639-640 (in Chinese).

18. Lin $\mathrm{Y}$, Jiang AL. Development of self - regulated learning scale of nursing undergraduates. People's Liberation Army Nurs J. 2004;6:1-4 (in Chinese)

19. Mao HY, Jiang AL. Preparation of norm of selflearning ability scale of nursing students. J Nurs J. 2016;33:13-17 (in Chinese).

20. Rezaee R, Mosalanejad L. The effects of casebased team learning on students' learning, self regulation and self direction. Glob $J$ Health Sci. 2015;7:295-306.

21. Field L. An investigation into the structure, validity, and reliability of Guglielmino's self-directed learning readiness scale. Adult Educ Q. 1989;39:125-139.

22. Candy PC. Self-Direction for Lifelong Learning. A Comprehensive Guide to Theory and Practice. San Francisco, CA: Jossey-Bass; 1991.

23. Falk $\mathrm{K}$, Falk $\mathrm{H}$, Jakobsson Ung $\mathrm{E}$. When practice precedes theory - A mixed methods evaluation of students' learning experiences in an undergraduate study program in nursing. Nurse Educ Pract. 2016;16:14-19.

24. Leatemia LD, Susilo AP, van Berkel H. Self-directed learning readiness of Asian students: students perspective on a hybrid problem based learning curriculum. Int J Med Educ. 2016;7:385-392.

25. Lestari E, Widjajakusumah D. Students' selfdirected learning readiness, perception toward student-centered learning and predisposition towards student-centered behavior. South-East Asian J Med Educ. 2009;3:52-56.

26. American Association of the Colleges of Nursing (AACN). Core Competencies for Inter-Professional Collaborative Practice: Report of an Expert Panel. Washington, DC: Interprofessional Education Collaborative; 2011.

27. Tan E, Brainard A, Larkin GL. Acceptability of the flipped classroom approach for in-house teaching in emergency medicine. Emerg Med Australas. 2015;27:453-459.

28. Herreid CF, Schiller NA. Case studies and the flipped classroom. J College Sci Teach. 2013;42:62-67.

29. O'Flaherty J, Phillips C. The use of flipped classrooms in higher education: A scoping review. Internet Higher Educ. 2015;25:85-95.

30. Higgins J, Green SE. Cochrane Handbook for Systematic Reviews of Interventions Version 5.1.0. Wiley-Blackwell; 2011:S38. 
31. Chen SZ, Zhou JM, Jiang ZX, Wei QM, Jiang DY, Lou D. Application of mixed learning concept in the teaching of flip classroom. Nurs Res. 2017;31:608610 (in Chinese).

32. Deng WF. Application research of flipped classroom teaching mode based on constructivism theory in introduction to nursing science. Chin J Pract Nurs. 2016;32:1429-1433 (in Chinese).

33. Hui YJ. Effects of flipped classroom teaching in clinical nursing teaching in higher vocational colleges. Chin J Continuing Med Educ. 2017;9:16-19 (in Chinese).

34. Jing J, Li L. Flip classroom in the assessment of health assessment of technical symptoms of the implementation of the teaching and thinking. Health Vocational Educ. 2017;35:143-144 (in Chinese).

35. Liu GL, Di XL, Liu YY, Xiang L. Application of tumbling classroom teaching model in rehabilitation nursing teaching. Nurs Res. 2017;31:2010-2011 (in Chinese).

36. Song YL, Liu XT, Liu W, et al. Application and evaluation of flipped classroom based on case teaching method in the teaching of basic nursing practice. $J$ Nurs China. 2016;9:8-11 (in Chinese).

37. Tian ZJ, Jin RH, Liu CF. Application of flipped classroom in nursing of old age nursing. Chin $J$ Nurs Educ. 2015;12:333-335 (in Chinese).

38. Wang FL. Application of flipped classroom combined with osce teaching model in clinical nursing teaching. Nurs Res. 2016;30:4291-4293 (in Chinese).
39. Zong MZ, Cong RZ, Li FJ, Liu YH. The application of the course of micro-class and flipped classroom in the teaching of basic nursing practice. World Latest Med Info. 2016;3:198 (in Chinese).

40. Liu P, Xue M, Ma LD, Li J. Effects of reversing classroom teaching on self-regulated learning ability of nursing students in higher vocational colleges. Chin J Nurs Educ. 2016;13:109-112 (in Chinese).

41. Ding JY, Wang LH, Wang C. Flip classroom in pediatric nursing teaching application. Health Vocational Educ. 2016;4:100-102 (in Chinese).

42. Presti CR. The flipped learning approach in nursing education: a literature review. J Nurs Educ. 2016;55:252-257.

43. Betihavas V, Bridgman $\mathrm{H}$, Kornhaber R, Cross $\mathrm{M}$. The evidence for 'flipping out': a systematic review of the flipped classroom in nursing education. Nurse Educ Today. 2016;38:15-21.

44. Tolks D, Schäfer C, Raupach T, et al. An introduction to the inverted/flipped classroom model in education and advanced training in medicine and in the healthcare professions. GMS J Med Educ. 2016;33:Doc46.

45. Green RD, Schlairet MC. Moving toward heutagogical learning: illuminating undergraduate nursing students' experiences in a flipped classroom. Nurse Educ Today. 2017;49:122-128.

46. Yue M, Zhang M, Zhang C, Jin C. The effectiveness of concept mapping on development of critical thinking in nursing education: a systematic review and meta-analysis. Nurse Educ Today. 2017;52:87-94.

Cited information: Liu Y-Q, Li Y-F, Lei M-J, Liu P-X, Theobald J, Meng L-N, Liu T-T, Zhang C-M, Jin C-D. Effectiveness of the flipped classroom on the development of self-directed learning in nursing education: a meta-analysis. Front Nurs. 2018; 4: 317-330. https://doi.org/10.1515/fon-2018-0032. 